\title{
Plasmodium falciparum gametocyte carriage, emergence, clearance and population sex ratios in anaemic and non-anaemic malarious children
}

\author{
Grace Olusola Gbotosho ${ }^{1}$, Akintunde Sowunmi ${ }^{1 /}$, Titilope Modupe Okuboyejo ${ }^{1}$, \\ Christian Tientcha Happi', Obaro Stanley Michael', \\ Onikepe Abiola Folarin ${ }^{1}$, Elsie Olufunke Adewoye ${ }^{2}$ \\ ${ }^{1}$ Department of Pharmacology and Therapeutics, Institute for Medical Research and Training \\ ${ }^{2}$ Department of Physiology, University of Ibadan, Ibadan, Nigeria
}

\begin{abstract}
Anaemia in falciparum malaria is associated with an increased risk of gametocyte carriage, but its effects on transmission have not been extensively evaluated in malarious children. Plasmodium falciparum gametocyte carriage, emergence, clearance, population sex ratios (SR) (defined as the proportion of gametocytes that are male), inbreeding rates and temporal changes in SR were evaluated in 840 malarious children. Gametocyte carriage pretreatment was at a level of $8.1 \%$. Anaemia at enrolment was an independent risk factor for gametocyte carriage post-treatment. The emergence of gametocytes seven days post-treatment was significantly more frequent in anaemic children (7/106 vs. 10/696, $p=0.002)$. In the initially detected gametocytes, the proportion of children with a male-biased SR (MBSR) (> 0.5) was significantly higher in anaemic children (6/7 vs. 3/10, $p=0.027)$. Pre-treatment $S R$ and estimated inbreeding rates (proportion of a mother's daughters fertilised by her sons) were similar in anaemic and non-anaemic children. Pre-treatment SR became more female-biased in non-anaemic children following treatment. However, in anaemic children, SR became male-biased. Anaemia was shown to significantly increase gametocyte emergence and may significantly alter the SR of emerging gametocytes. If MBSR is more infective to mosquitoes at low gametocytaemia, then these findings may have significant implications for malaria control efforts in endemic settings where malaria-associated anaemia is common.
\end{abstract}

Key words: Plasmodium falciparum - gametocytes - sex ratio - transmission - children

Anaemia is a common complication of Plasmodium falciparum infections and a major contributor to morbidity and, to a lesser extent, mortality in children from areas endemic for P. falciparum (Murphy \& Breman 2001, Crawley 2004, Nkuo-Akenji et al. 2006, Sowunmi et al. 2010). This condition is due, in part, to the destruction of infected erythrocytes, a shortened survival of uninfected erythrocytes and bone marrow dyserythropoiesis (White \& Ho 1992, Price et al. 2001). P. falciparum-related anaemia is also often associated with an increased risk of gametocyte carriage (Price et al. 1999, von Seidlein et al. 2001).

Malaria transmission from the mosquito to human host requires the uptake and development of $P$. falciparum into gametes within the mosquito. This is true of both the male and female Plasmodium spp gametocytes ingested by the mosquito via feeding on the blood of infected hosts (Sinden 1983). In the mosquito, a female

Financial support: Swiss Pharma Nigeria (to AS), FIRCA, UNICEF/ UNDP/WorldBank/WHO/TDR/PAG/South-South Initiative Project, HMI, EDCTP (to CTH), MIM/TDR (to GOG)

+ Corresponding author: akinsowunmi@hotmail.com

Received 23 December 2010

Accepted 6 June 2011 gametocyte develops into a single gamete, while a male gametocyte develops into a maximum of eight gametes (Sinden et al. 1978). Mosquito infectivity after a blood meal is dependent on gametocyte density in the respective blood meal (Tchuinkam et al. 1993) and may be impacted by the relative proportion of male gametocytes (Robert et al. 1996, Mitri et al. 2009). In this context, the gametocyte sex ratio (SR) (proportion of gametocytes that are male) (Pickering et al. 2000, West et al. 2001, 2002) plays a role in transmission success.

In natural populations, Plasmodium spp gametocyte SR are female-biased. However, this ratio can vary significantly and in some cases may become less femalebiased as the infection progresses and anaemia develops in the host (Paul et al. 2000). The ratio can also become less female-biased as a result of host immune response, changes in parasite density or competition from other parasite genotypes (clones) (Paul et al. 2000, Robert et al. 2003, Reece et al. 2005).

Although anaemia in P. falciparum infections may be associated with an increased risk of gametocyte carriage (Price et al. 1999, von Seidlein et al. 2001), the availability of gametocytes in peripheral blood of the human host (from which the mosquito obtains a blood meal) is dependent on the interplay of emergence and clearance of the gametocytes. This interplay may be perturbed by antimalarial drugs used for therapy (Sowunmi et al. 2009a) or host immunity. It is currently unclear how $P$. falciparum malaria-associated anaemia influences these processes 
and how the condition impacts the gametocyte SR in malarious children undergoing therapy with artemisinins or artemisinin-based combination therapies (ACTs).

In the present study, we evaluate the relationship between anaemia, gametocytaemia and gametocyte SR in a group of children with apparently uncomplicated $P$. falciparum malaria who live in an endemic area of southwestern Nigeria; all patients were treated with artesunate or ACTs. The main aims were as follows: (i) determine gametocyte carriage, emergence and clearance of $P$. falciparum gametocytaemia in anaemic and nonanaemic children, (ii) evaluate the influence of anaemia on the population structure of $P$. falciparum gametocyte SR and (iii) examine any differences in the temporal changes in gametocyte SR of anaemic and non-anaemic malarious children during therapy to accurately describe any potential effects on transmission.

\section{PATIENTS, MATERIALS AND METHODS}

Patients - Patients were recruited from 2005-2010 at the malaria clinic of the University College Hospital in Ibadan, southwestern Nigeria, which is an endemic area for malaria (Salako et al. 1990). Patients were placed into various antimalarial efficacy studies involving artesunate or ACTs. Patients were enrolled if the following criteria were met: age $0.5-15$ years, fever or history of fever in $24-48 \mathrm{~h}$ preceding presentation, pure $P$. falciparum parasitaemia $>2000 / \mu \mathrm{L}$ blood, absence of concomitant illness and written informed consent of a parent or guardian. Patients with severe malaria (Anon 2000) or serious underlying diseases (e.g., renal, cardiac or hepatic diseases) or severe malnutrition were excluded from the study. The study received approval from the local Ethics Committee (Ethics Committee, Ministry of Health, Ibadan, Nigeria).

Drug management - Drug treatment was administered according to standard schedules (Table I). Briefly, at presentation and for a few days after, depending on the treatment regimen, the children were given standard oral doses of artesunate or ACTs. At enrolment (day 0) and at follow-up days one-seven, 14, 21, 28, 35 and 42 , patients underwent full physical examination and thin and thick blood films were examined for quantification of asexual and sexual parasitaemia.

Laboratory investigations - Quantification of asexual and sexual parasites in thick films was completed against both 500 and 1,000 leukocytes, assuming a leukocyte count of $6,000 / \mu \mathrm{L}$ blood. Asexual parasite clearance time was measured as the time from the start of anti-malarial treatment until the asexual parasite count fell below detectable levels in a peripheral blood smear. Gametocyte clearance time was measured as the interval between the first and last positive gametocyte smears.

All gametocytes were sexed if gametocytaemia was $>10 / \mu \mathrm{L}$ in blood and according to the following criteria (Carter \& Graves 1988): males (microgametocytes) are smaller than females (macrogametocytes), the nucleus is larger in males than females, the ends of the cells are rounder in males and more angular in females, the cytoplasm stains purple in males and deep blue in females with Giemsa and the granules of malaria pigment are centrally located in females and more widely diffused in males. Gametocytes were sexed if at least three of the five criteria stated above were present. The SR was defined as the proportion of gametocytes in peripheral blood that were male (Pickering et al. 2000, West et al. 2001, 2002). The SR was considered to be male-biased if it was $>0.5$.

Capillary blood collected before and during followup was used to measure packed cell volume (PCV). PCVs were measured using a microhaematocrit tube and a microcentrifuge (Hawksley, Lancing, UK).

Data analysis - Data were analysed using version 6 of the Epi-Info software (Anon 1994) and the statistical programme SPSS for Windows version 10.01 (Anon 1999). Variables considered in the analysis were related to the densities of P. falciparum gametocytes and trophozoites. Proportions were compared by calculating $\chi^{2}$ with Yates' correction or by the Fisher exact test.

\section{TABLE I}

Treatment regimens during the study period

\begin{tabular}{|c|c|c|c|}
\hline Drugs & Regimens & $\begin{array}{l}\text { Children } \\
\text { (n) }\end{array}$ & Years \\
\hline $\begin{array}{l}\text { Artemether plus } \\
\text { lumefantrine }\end{array}$ & $\begin{array}{c}20 \mathrm{mg} / 120 \mathrm{mg} \text {, respectively; } 5-14 \mathrm{~kg} \text { received one tab., } 15-24 \mathrm{~kg} \text { two tab., } \\
25-34 \mathrm{~kg} 3 \mathrm{tab} .,>34 \mathrm{~kg} \text { four tab. at presentation } 8 \mathrm{~h} \text { later } \\
\text { and at } 24 \mathrm{~h}, 36 \mathrm{~h}, 48 \mathrm{~h} \text { and } 60 \mathrm{~h} \text { after first dose. }\end{array}$ & 246 & 2005-2006, 2009-2010 \\
\hline Artesunate & $4 \mathrm{mg} / \mathrm{kg}$ over three days. & 116 & 2006 \\
\hline $\begin{array}{l}\text { Artesunate plus } \\
\text { amodiaquine (cp) }\end{array}$ & $\begin{array}{l}\text { Artesunate given as in artesunate above plus amodiaquine; } \\
\qquad 10 \mathrm{mg} / \mathrm{kg} \text { over three days. }\end{array}$ & 214 & $2006,2009-2010$ \\
\hline $\begin{array}{l}\text { Artesunate plus } \\
\text { amodiaquine (cf) }\end{array}$ & $\begin{array}{l}50 \mathrm{mg} \text { cf with } 270 \mathrm{mg} \text {, respectively; } 5-15 \mathrm{~kg} \text { received } 0.5 \text { tab., } \\
15-25 \mathrm{~kg} \text { one tab., } 25-34 \mathrm{~kg} 1.5 \text { tab., }>34 \mathrm{~kg} \text { two tabs. }\end{array}$ & 69 & $2009-2010$ \\
\hline $\begin{array}{l}\text { Artesunate plus } \\
\text { mefloquine }\end{array}$ & $25 \mathrm{mg} / \mathrm{kg}$ at presentation plus artesunate as given above. & 158 & $2007-2008$ \\
\hline
\end{tabular}

cf: coformulated; cp: co-packaged. 
Normally distributed continuous data were compared by Student's $t$-test and analysis of variance. Data not conforming to a normal distribution were compared using the Mann-Whitney U-test, the Kruskal-Wallis test or the Wilcoxon ranked sum test. The relationship between the gametocyte SR and clinical or parasitological parameters was assessed via linear regression. A multiple logistic regression model was used to test the association between gametocytaemia (yes or no at presentation or following treatment) and factors that were significant at univariate analysis (i.e., age, haematocrit and parasite density). Because the study was conducted over a period of five years, time in years since the commencement of study was included as a covariate in the model. $p$ values of $<0.05$ were considered to be statistically significant. Data were (double) entered serially using the patients' codes and were only analysed at the completion of the study.

\section{RESULTS}

Patients - Eight hundred and forty children with acute malaria caused by P. falciparum infection were included in the study for the purpose of multivariate analysis of risk factors for gametocyte carriage. Of these, 802 had haematocrit measurements. The characteristics of the 802 children with acute malaria who were enrolled in the study are illustrated in Table II. Asexual parasitaemia cleared within two days in both anaemic and nonanaemic children (Table II).

Risk factors for gametocyte carriage at presentation - Table III illustrates that age of $<$ three years, haematocrit of $<25 \%$, parasitaemia of $<50,000 / \mu \mathrm{L}$ blood and enrolment before 2009 were associated with increased risk for gametocyte carriage at presentation. In addition, age of $<$ three years and enrolment before 2009 were independent risk factors for gametocyte carriage.

TABLE II

Demographic data and immediate therapeutic response of children with or without Plasmodium falciparum-associated anaemia treated with artemisinin-based combination therapies

\begin{tabular}{|c|c|c|c|}
\hline Variables & $\begin{array}{l}\text { Anaemia } \\
(\mathrm{n}=106)\end{array}$ & $\begin{array}{l}\text { No anaemia } \\
\quad(\mathrm{n}=696)\end{array}$ & $\mathrm{p}$ value \\
\hline Age (years) [mean (SEM)] & $5(0.26)$ & $6.8(0.11)$ & 0.0001 \\
\hline Male/female & $48 / 58$ & $348 / 337$ & \\
\hline$<3$ years & 23 & 52 & $<0.0001$ \\
\hline$<5$ years & 29 & 135 & 0.078 \\
\hline Weight (kg) [mean (SEM)] & $15.4(0.51)$ & $18.8(0.25)$ & $<0.0001$ \\
\hline Height (cm) [mean (SEM)] & $110.8(2.8)$ & $130.6(15.4)$ & $<0.0001$ \\
\hline Duration of illness (days) [mean (SEM)] & $3.3(0.19)$ & $2.7(0.05)$ & 0.06 \\
\hline$<2$ days & 17 & 244 & 0.001 \\
\hline$>2$ days & 54 & 304 & \\
\hline Temperature (day zero) $\left({ }^{\circ} \mathrm{C}\right)[$ mean $(\mathrm{SEM})]$ & $38.6(0.12)$ & $38.4(0.04)$ & 0.85 \\
\hline$\geq 40^{\circ} \mathrm{C}$ & 12 & 52 & 0.23 \\
\hline PCV on day $0(\%)[$ mean $(\mathrm{SEM})]$ & $22.7[0.23]$ & $32.4[0.14]$ & 0.000 \\
\hline GMPD $(/ \mu \mathrm{L}$ of blood $)$ & 53,305 & 554,941 & 0.98 \\
\hline Range & $2,563-1,183,145$ & $2,837-1,125,000$ & \\
\hline$<50,000$ & 47 & 285 & 0.58 \\
\hline $50,000-100,000$ & 11 & 57 & 0.58 \\
\hline$>100,000-250,000$ & 18 & 150 & 0.34 \\
\hline$>250,000$ & 25 & 159 & 0.96 \\
\hline GMGD (/ $\mu \mathrm{L}$ of blood) & 13 & 29 & 0.03 \\
\hline Range & $6-54$ & $6-444$ & \\
\hline$<20 / \mu \mathrm{L}$ & 8 & 34 & 0.35 \\
\hline Gametocyte carriage & 10 & 58 & 0.75 \\
\hline $0-<2$ years & 2 & 6 & 0.66 \\
\hline $2-<5$ years & 3 & 19 & 0.24 \\
\hline$<2$ days & 4 & 23 & 0.81 \\
\hline$>2$ days & 1 & 15 & 0.63 \\
\hline Fever clearance time (days) & $1.2 \pm 0.5(\mathrm{n}=75)$ & $1.1 \pm 0.4(\mathrm{n}=563)$ & 0.65 \\
\hline Parasite clearance time (days) & $1.3 \pm 0.6$ & $1.1 \pm 0.6$ & 0.14 \\
\hline
\end{tabular}

GMGD: geometric mean gametocyte density; GMPD: geometric mean parasite density; PCV: packed cell volume; SEM: standard error of mean. 
TABLE III

Risk factors for gametocyte carriage at presentation in children enrolled in the study

\begin{tabular}{|c|c|c|c|c|c|c|}
\hline Variable & $\begin{array}{l}\text { Children } \\
\text { (n) }\end{array}$ & $\begin{array}{l}\text { Children with gametocytes } \\
\text { (n) }\end{array}$ & $\begin{array}{l}\text { Crude OR } \\
(95 \% \mathrm{CI})\end{array}$ & $\mathrm{p}$ value & $\begin{array}{l}\text { Adjusted OR } \\
(95 \% \mathrm{CI})\end{array}$ & $\mathrm{p}$ value \\
\hline \multicolumn{7}{|l|}{ Age (years) } \\
\hline$\geq 3$ & 745 & 57 & 1 & \multirow[t]{2}{*}{0.007} & 1 & \multirow[t]{2}{*}{0.044} \\
\hline$<3$ & 78 & 13 & $2.41(1.25-4.64)$ & & $2.03(1.01-4.05)$ & \\
\hline \multicolumn{7}{|c|}{ Haematocrit (\%) } \\
\hline$\geq 25$ & 638 & 10 & 1 & \multirow[t]{2}{*}{0.001} & 1 & \multirow[t]{2}{*}{0.61} \\
\hline$<25$ & 96 & 7 & $4.93(1.83-13.3)$ & & $0.82(0.39-1.72)$ & \\
\hline \multicolumn{7}{|c|}{ Parasite density $(/ \mu \mathrm{L})$} \\
\hline$\geq 50,000$ & 438 & 28 & 1 & \multirow[t]{2}{*}{0.018} & 1 & \multirow[t]{2}{*}{0.19} \\
\hline$<50,000$ & 351 & 39 & $1.83(1.10-3.04)$ & & $1.42(0.83-2.41)$ & \\
\hline \multicolumn{7}{|c|}{ Year of enrolment } \\
\hline After 2009 & 435 & 14 & 1 & \multirow[t]{2}{*}{$<0.0001$} & 1 & \multirow[t]{2}{*}{$<0.001$} \\
\hline Before 2009 & 405 & 56 & $4.82(2.64-8.81)$ & & $4.20(2.09-8.44)$ & \\
\hline
\end{tabular}

CI: confidence interval; OR: odds ratio.

TABLE IV

Risk factors for gametocyte carriage following treatment

\begin{tabular}{|c|c|c|c|c|c|c|}
\hline Variable & $\begin{array}{l}\text { Children } \\
\text { (n) }\end{array}$ & $\begin{array}{l}\text { Children with gametocytes } \\
\text { (n) }\end{array}$ & $\begin{array}{l}\text { Crude OR } \\
(95 \% \mathrm{CI})\end{array}$ & $\mathrm{p}$ value & $\begin{array}{l}\text { Adjusted OR } \\
\quad(95 \% \mathrm{CI})\end{array}$ & $\mathrm{p}$ value \\
\hline \multicolumn{7}{|l|}{ Age (year) } \\
\hline$\geq 3$ & 745 & 18 & 1 & \multirow[t]{2}{*}{0.93} & \multirow[t]{2}{*}{-} & \multirow[t]{2}{*}{-} \\
\hline$<3$ & 78 & 2 & $1.06(0.24-4.66)$ & & & \\
\hline \multicolumn{7}{|c|}{ Haematocrit at enrolment (\%) } \\
\hline$\geq 25$ & 696 & 10 & 1 & \multirow[t]{2}{*}{0.001} & 1 & \multirow[t]{2}{*}{0.009} \\
\hline$<25$ & 106 & 7 & $4.85(1.8-13.0)$ & & $3.82(1.4-0.43)$ & \\
\hline \multicolumn{7}{|c|}{ Parasite clearance time (d) } \\
\hline$\leq 1$ & 612 & 13 & 1 & \multirow[t]{2}{*}{0.35} & \multirow[t]{2}{*}{-} & \multirow[t]{2}{*}{-} \\
\hline$>1$ & 216 & 7 & $1.54(0.6-3.92)$ & & & \\
\hline \multicolumn{7}{|c|}{ Year of enrolment } \\
\hline After 2009 & 435 & 3 & 1 & \multirow[t]{2}{*}{0.001} & 1 & \multirow[t]{2}{*}{0.025} \\
\hline Before 2009 & 405 & 17 & $6.30(1.83-21.69)$ & & $4.20(1.19-15.1)$ & \\
\hline
\end{tabular}

CI: confidence interval; OR: odds ratio.

Risk factors for gametocyte carriage following treatment - Table IV illustrates that anaemia at enrolment and enrolment before 2009 were associated with an increased risk of gametocyte carriage following treatment. These two factors were also shown to be independent risk factors for gametocyte carriage following treatment.

First detection of gametocyte - At enrolment, gametocytes were detected in 68 patients. Specifically, gametocytes were detected in 10 of 106 children with anaemia and 58 of 696 children without anaemia. The difference in proportion of gametocyte carriers was not statistically significant $(p=0.24)$. Seven days after the initiation of treatment, gametocytes were detected in another 17 children. At this point, detection was significantly higher in anaemic than non-anaemic children (7 of 106 vs. 10 of
$696, \chi^{2}=9.48, \mathrm{p}=0.002$ ) (Table V). Overall, gametocyte carriage before and after treatment was similar in anaemic children ( 10 of 106 vs. 17 of $106, \chi^{2}=1.53, p=0.2$ ). Gametocyte carriage before and after treatment in nonanaemic children was also similar (58 of 696 vs. 68 of $\left.696, \chi^{2}=0.71, p=0.4\right)$. In the initially detected gametocytes, the proportion of children with a male-biased SR was significantly higher in anaemic children (6 of 7 vs. 3 of $10, p=0.027$ by Mantel Haenszel test or $p=0.049$ by Fisher exact test). By day 42, only one child with anaemia carried gametocytes.

Clearance of gametocytaemia - Rates of gametocytaemia clearance are presented in Table VI. Gametocyte clearance times were similar in both anaemic and nonanaemic children (2.1 vs. $2.4, \mathrm{p}=0.5$ ). 


\section{TABLE V}

First appearance of gametocytes in anaemic and non-anaemic children with Plasmodium falciparum infections treated with artemisinin-based combination therapies

Children with gametocytes

(n)

\begin{tabular}{lccccc}
$\begin{array}{l}\text { Day after } \\
\text { enrolment }\end{array}$ & $\begin{array}{c}\text { Anaemia } \\
(\mathrm{n}=106)^{a}\end{array}$ & $\begin{array}{c}\text { No anaemia } \\
(\mathrm{n}=696)^{a}\end{array}$ & $\begin{array}{c}\text { Children } \\
(\mathrm{n})\end{array}$ & $\begin{array}{c}\text { Cumulative } \\
(\%)\end{array}$ & $\begin{array}{c}\mathrm{p} \text { value } \\
0\end{array}$ \\
\hline 10 & 58 & 68 & 80 & 0.85 \\
1 & 1 & 5 & 6 & 91 & 0.63 \\
2 & 2 & 1 & 3 & 92 & 0.06 \\
3 & 0 & 1 & 2 & 94 & 0.28 \\
4 & 1 & 1 & 1 & 95 & 0.62 \\
5 & 0 & 1 & 3 & 99 & 0.28 \\
6 & 2 & 0 & 1 & 100 & 0.06 \\
7 & 1 & $68^{a}$ & 85 & 100 & 0.28 \\
\hline Total & $17^{a}$ & 1 & 28 & 0.002 \\
\hline
\end{tabular}

$a$ : proportion of emerged gametocyte with a sex ratio $\geq 0.5$ in children with or without anaemia was six of seven and three of 10 , respectively ( $p=0.049$ by Fisher exact test or $p=0.027$, by Mantel Haenszel test).

\section{TABLE VI}

Clearance of gametocytes following treatment of Plasmodium falciparum infections with artemisinin-based combination therapies in children with or without anaemia

\begin{tabular}{lccc}
\hline $\begin{array}{l}\text { Day of } \\
\text { clearance }\end{array}$ & $\begin{array}{c}\text { Anaemia } \\
(\mathrm{n}=106)\end{array}$ & $\begin{array}{c}\text { No anaemia } \\
(\mathrm{n}=696)\end{array}$ & $\mathrm{p}$ value \\
\hline 1 & 11 & 33 & 0.36 \\
2 & 0 & 11 & 0.27 \\
3 & 2 & 5 & 0.91 \\
4 & 2 & 9 & 0.65 \\
5 & 1 & 0 & 0.35 \\
6 & 1 & 7 & 0.43 \\
7 & 0 & 2 & - \\
GCT (median) & 1 & 2 & \\
Mean \pm SEM (days) & $2.1 \pm 0.4$ & $2.4 \pm 0.2$ & 0.52 \\
Range & $1-6$ & $1-7$ & \\
\hline
\end{tabular}

GCT: gametocyte clearance time; SEM: standard error of mean.

Relationship between gametocyte density and gametocyte SR at enrolment - In general, using a reliable estimate for the measurement of SR when gametocyte density was $\geq 15 / \mu \mathrm{L}$ of blood, there was no significant relationship between gametocyte density and SR ( $\mathrm{r}=$ $-0.035, p=0.82$ ). In anaemic children, the corresponding $\mathrm{r}$ value was -0.497 with $\mathrm{p}=0.67$. In non-anaemic children, $\mathrm{r}$ was equal to -0.001 with $\mathrm{p}=0.99$.

Population structure of P. falciparum gametocyte SR Fig. 1 (day 0) highlights the pre-treatment distribution of $P$. falciparum SR in children with or without anaemia. Overall, in all gametocyte carriers, the weighted mean population SR was equal to 0.38 [95\% confidence
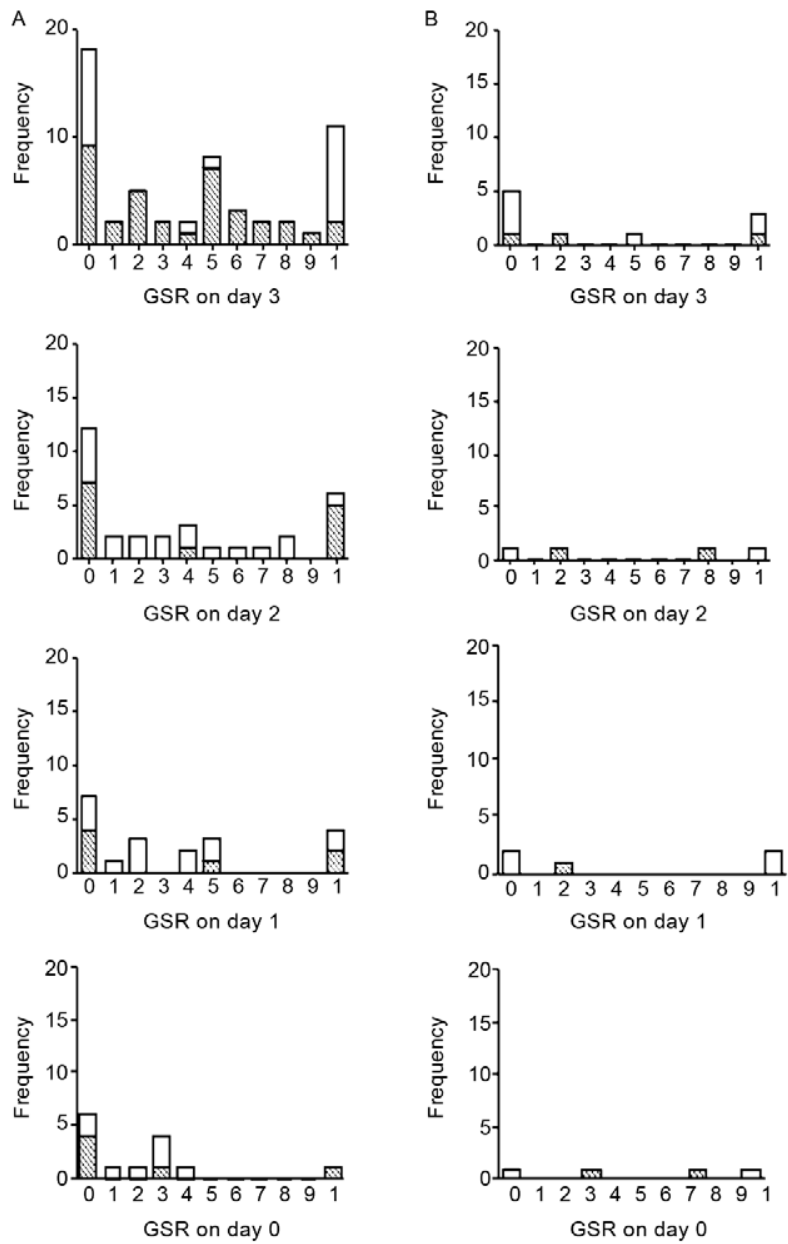

Fig. 1: frequency distribuition of Plasmodium falciparum gametocyte sex ratios (GSR) pre-treatment and during follow-up in children without anaemia (A) or with anaemia (B). Hatched portions of bars refer to gametocyte carriers in whom the gametocyte densities $=15 / \mu \mathrm{L}$ blood. 


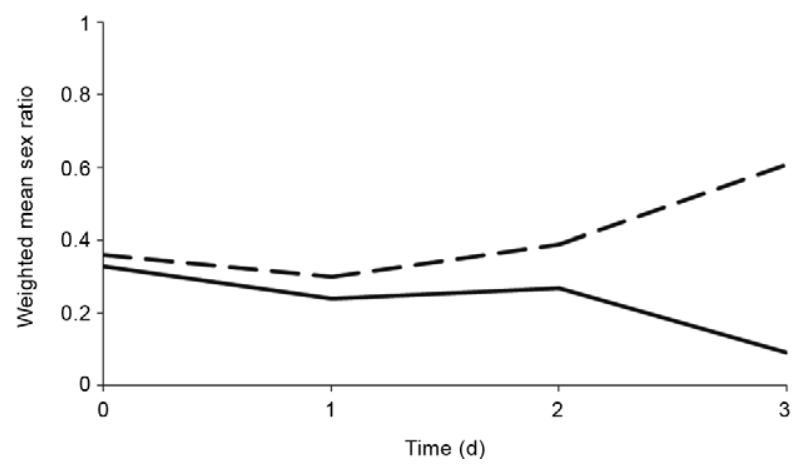

Fig. 2: temporal changes in gametocyte sex ratios following treatment of anaemic (broken line) and non-anaemic (solid line) children with artemisinin-based combination therapies.

interval (CI) of 0.31-0.44]. If a more reliable estimate of gametocyte density of $>15 / \mu \mathrm{L}$ was used, the mean population SR in gametocyte carriers was $0.34(95 \% \mathrm{CI}$ of 0.22-0.46), which corresponds to two female to each male. Based on these findings, the inbreeding rate given by the equation, $f=1-2 z^{*}$ (West et al. 2001), where $z^{*}$ is the proportion of male relative to female, is $0.32(95 \%$ CI of 0.10-0.56). Using reliable estimates, the weighted mean SR in anaemic and non-anaemic children were 0.36 (95\% CI of $0.1-0.5)$ vs. 0.33 (95\% CI of $0.24-0.44$, $\mathrm{p}=0.96)$. The corresponding inbreeding rates were also similar in anaemic and non-anaemic children $(0.28,95 \%$ CI of $0.1-0.9$ vs. $0.34,95 \%$ CI of $0.1-0.5, p=0.94$ ).

In anaemic children, extremes of SR were as follows: 0 in five children (50\%) and 1 in three children (30\%); SR of 0.5 was seen in one child (10\%). In non-anaemic children, extremes of SR were as follows: 0 in 18 children (31\%) and 1 in 11 children (19\%); SR of 0.5 was seen in eight children (13\%).

Temporal changes in SR following treatment - Temporal changes in SR following treatment are shown in Fig. 2 (see also Fig. 1). These changes were similar on days one and two in anaemic and non-anaemic children. However, three days following treatment, the weighted mean SR was significantly lower and more female-biased in nonanaemic children in comparison to anaemic children $(0.61$, range $0.29-0.89$ vs. 0.09 , range $0-1, p=0.027$ ). In anaemic children, the frequency of a male-biased SR (i.e., SR $\geq 0.5$ ) was 4 on day zero and 2 on day three $(p=1.0)$. In nonanaemic children, the frequency of male-biased SR was 21 on day zero and 1 on day three $(\mathrm{p}=0.005)$.

\section{DISCUSSION}

In the present study, anaemia was common in young children and was associated with an increased risk for gametocyte carriage at presentation. However, anaemia was not an independent risk factor for gametocyte carriage at presentation. These results differ from findings in other endemic and non-endemic areas, where others have shown anaemia to be an independent risk factor for gametocyte carriage (Price et al. 1999, von Seidlein et al.
2001). The association with increased risk of gametocyte carriage also differs from a previous report from this endemic area (Sowunmi et al. 2004).

Following treatment, anaemia and enrolment before 2009 were independent risk factors for gametocyte carriage. The result that anaemia was an independent risk factor for carriage gametocyte following treatment was not surprising because it was associated with an increased release of predominantly male gametocyte (Table V).

In most malarious children and adults, virtually all of the gametocytes seen in the periphery emerge within one-week after the initiation of treatment (Piyaphanee et al. 2006, Sowunmi et al. 2009c). In the present cohort, over $95 \%$ of the gametocytes had emerged in the periphery by day five post-treatment. However, the emergence of gametocytes was significantly more frequent in anaemic compared with non-anaemic children, thus suggesting that anaemia significantly impacts the release of gametocytes into circulation. Although the viability of the emerging gametocytes was not evaluated, if they were viable, ingestion by the mosquito vector would be expected to contribute to transmission, at least during the first week following commencement of treatment. Anaemia may trigger the conversion of asexual parasites into gametocytes in vitro (Ifediba \& Vanderberg 1981). It is plausible that this process preceded the release into the peripheral circulation during the first week of observation in this cohort of children. However, the exact reasons are not apparent from the current data. If this were the case, then it may explain the significantly more frequent emergence of gametocytes in anaemic children during the first week of follow-up. A remote possibility is that the artemisinin derivatives in ACTs accelerate the conversion of asexual parasites into gametocytes and clear these gametocytes rapidly. This conversion process may be more pronounced in anaemic children.

An intriguing finding is that despite significant differences in the emergence of gametocytes, the clearance of gametocytes from the peripheral circulation was similar in both groups. Clearance of gametocytes from the peripheral blood results from the interplay of host, parasite and drug factors. In endemic areas, the clearance of drug-resistant asexual parasites is enhanced by immunity (Djimde et al. 2003) and it has been suggested that immunity may also enhance gametocyte clearance in children from this endemic area (Sowunmi et al. 2009c). If the latter is true, it would appear that the similar gametocyte clearance rates between the relatively younger anaemic and the relatively older non-anaemic children may suggest that the younger anaemic children may possess a certain degree of immunity that is perhaps as good as in the older children. Another alternative is that clearance of gametocytes following ACTs is only slightly influenced by age or haematocrit level. This latter explanation is expected because the clearance of asexual parasitaemia was similar in anaemic and nonanaemic children (Table II).

Population structure analysis of gametocyte SR at enrolment showed that the weighted SR and inbreeding rates were similar in anaemic and non-anaemic children. These findings suggest a relative lack of effect of anae- 
mia on transmission in this cohort. The overall weighted mean population SR of 0.34 and of 0.32 and 0.33 , respectively, in anaemic and non-anaemic children, suggest that the maximum degree of female bias expected if the number of viable gametes released after ex-flagellation by one male gametocyte was approximately 2 (Read et al. 1992). In this context, it would appear that the presence of anaemia at presentation in these children did not provoke a significant degree of ex-flagellation. The reasons for this observation remain unclear. The maximum degree of gametes released was found to be less than 3.5, which is the amount recently reported in the same area of study (Sowunmi et al. 2009b). Additionally, this SR value is higher than that reported from both Cameroun (0.217) (Robert et al. 1996) and Papua New Guinea (0.18) (Paul et al. 1995), but somewhat similar to that reported from Senegal (0.346) (Robert et al. 2003).

Interestingly, in half of the anaemic children and one third of the non-anaemic children, no male gametocytes were found. Similarly, in one third of the anaemic children and in one fifth of the non-anaemic children, no female gametocytes were found. With both SR extremes, it is difficult to conceive of how these parasites would transmit. Obviously, in terms of overall proportion, parasite non-transmissibility is similar in anaemic and non-anaemic children. The very low frequency of SR of 0.5 at enrolment in anaemic and non-anaemic children suggests that gamete combination from multiple genotypes (clones), which maximises genetic representation of each clone in the zygote population, is uncommon. Proportion-wise, this should influence the fitness of the parasite to transmit. The low frequency of a SR of 0.5 in the pre-treatment parasite populations suggests that, overall, inbreeding is relatively common. Inbreeding rates in our data series were calculated from the SR data, a relatively inexpensive and facile method of indirectly estimating this rate (Nee et al. 2002).

It is generally known that during animal infections, a female-biased SR decreases as a response to anaemia, parasite density, host immune response or competition from other parasite genotypes (Paul et al. 2000, Reece et al. 2008, Sowunmi et al. 2009b). Although competition from other parasite genotypes was not evaluated in the present study, a less female-biased SR was observed in anaemic children when compared to non-anaemic children during follow-up. The possible reasons for this observation are as follows: an increased erythropoietin (EPO) secretion and release in anaemic children [in lower animals, increased (EPO) in secretion in response to anaemia is associated with a less female-biased sex allocation] (Paul et al. 2000) and a blunting of the tendency of ACTs to selectively favour the emergence of a female-biased SR following treatment (Sowunmi et al. 2007, 2009a). In the latter context, further exploration of the interaction(s) between anaemia and ACT treatment on SR is urgently needed. There may be significant policy implications of the present findings in regions where malaria-associated anaemia is common and where ACTs, the recommended first line treatment of malaria globally (WHO 2001), are used. Artemisinin drugs are gametocytocidal for immature, but not mature gametocytes (Kumar \& Zheng 1990), and ACTs reduce mosquito infectivity following treatment when compared to non-ACTs (Sutherland et al. 2005, Okell et al. 2008). It follows that early diagnosis and prompt treatment of infection using ACTs may aid in this setting.

In general, gametocytaemia was low in the present cohort of children (Table II). If increasingly male SR do give higher transmission success at lower gametocytaemia (Mitri et al. 2009), it is conceivable that in malariaendemic areas, where malarial anaemia is relatively common and is associated with increased risk of gametocyte carriage, transmission may be enhanced in anaemic children, provided that the gametocytes are viable. Therefore, our findings may have significant implications for malaria control in many endemic countries/regions.

There are limitations of our study. One such limitation is that EPO levels were not measured; it was therefore impossible to relate the changes in gametocyte emergence and SR to EPO secretion. A further limitation was the lack of clonal data in the children, thus making it difficult to assess the relationship between anaemia, clonal multiplicity and SR. Further studies are now needed to determine whether gametocytes obtained from anaemic children from this endemic area are more infectious to mosquitoes than those from non-anaemic children. Determination of whether submicroscopical gametocytaemia is more common in anaemic children is also warranted.

\section{REFERENCES}

Anon 1994. Epi Info version 6. A Word processing data base and statistics program for public health on IBM-compatible microcomputers. Centers for Disease Control and Prevention, Atlanta, GA, USA.

Anon 1999. SPSS for Windows Release 10.01 (standard version). SPSS Inc Chicago, IL, USA.

Anon 2000. World Health Organization: severe falciparum malaria. Trans R Soc Trop Med Hyg 94 (Suppl. 1): S1-S90.

Carter R, Graves PM 1988. Gametocytes. In WH Wernsdorfer, Malaria: principles and practice of malariology, vol. I, Churchill Livingstone, Edinburgh, p. 253-303.

Crawley J 2004. Reducing the burden of anaemia in infants and young children in malaria-endemic countries of Africa: from evidence to action. Am J Trop Med Hyg 71 (Suppl. 2): 25-34.

Djimde AA, Doumbo OK, Traore O, Guindo AB, Kayentao K, Diourte Y, Niare-Dumbo S, Coulibaly D, Kone AK, Cissoko Y, Tekete M, Diallo DA, Wellems TE, Kwiatowski D, Plowe CV 2003. Clearance of drug-resistant parasites as a model for protective immunity in Plasmodium falciparum malaria. Am J Trop Med Hyg 69: 558-563.

Ifediba T, Vanderberg JP 1981. Complete in vitro maturation of Plasmodium falciparum gametocytes. Nature 294: 364-366.

Kumar N, Zheng H 1990. Stage-specific gametocytocidal effect in vitro of the antimalarial drug quighaosu on Plasmodium falciparum. Parasitol Res 76: 214-218.

Mitri C, Thiery MI, Bourgouin C, Paul REL 2009. Density-dependent impact of the human malaria parasite Plasmodium falciparum. Proc R Soc B 276: 3721-3726.

Murphy SC, Breman JG 2001. Gaps in the childhood malaria burden in Africa: cerebral malaria, neurological sequelae, anaemia, 
respiratory distress, hypoglycemia, and complications of pregnancy. Am J Trop Med Hyg 64 (Suppl. 1, 2): 57-67.

Nee S, West SA, Read AF 2002. Inbreeding and parasite sex ratios. Proc R Soc B 269: 755-760.

Nkuo-Akenji TK, Chi PC, Cho JF, Ndamukong JK, Sumbele I 2006. Malaria and helminth co-infection in children living in a malaria endemic setting of mount Cameroon and predictors of anaemia. J Parasitol 92: 1191-1195.

Okell LC, Drakeley CJ, Ghani AC, Bousema T, Sutherland CJ 2008. Reduction of transmission from malaria patients by artemisinin combination therapies: a pooled analysis of six randomized trials. Malaria J 7: 125 .

Paul REL, Coulson TN, Raibaud A, Brey PT 2000. Sex determination in malaria parasites. Science 287: 128-131.

Paul REL, Packer MJ, Walmsley M, Lagog M, Randford-Cartwright LC, Paru R, Day KP 1995. Mating patterns in malaria parasite populations of Papua New Guinea. Science 269: 1709-1711.

Pickering J, Read AF, Guerrero S, West SA 2000. Sex ratio and virulence in two species of lizard malaria parasites. Evol Ecol Res 2: 171-184.

Piyaphanee W, Krudsood S, Tangpukdee N, Thanachartwet W, Silachamroon U, Phophak N, Duangdee C, Haoharn O, Faithong S, Wilairatana P, Leowattana W, Looaresuwan S 2006. Emergence and clearance of gametocytes in uncomplicated Plasmodium falciparum malaria. Am J Trop Med Hyg 74: 432-435.

Price RN, Nosten F, Simpson JA, Luxemburger C, Paiphun L, ter Kuile TO, Chongsuphajasiddhi T, White NJ 1999. Risk factors for gametocyte carriage in uncomplicated falciparum malaria. Am J Trop Med Hyg 60: 1019-1023.

Price RN, Simpson JA, Nosten FO, Luxemburger C, Hkirjaroen L, Kuile FT, Chongsuphajaisiddhi T, White NJ 2001. Factors contributing to anaemia after uncomplicated falciparum malaria. $\mathrm{Am}$ J Trop Med Hyg 65: 614-622.

Read AF, Narara A, Nee S, Keymer AE, Day KP 1992. Gametocyte sex ratios as indirect measures of outcrossing rates in malaria. Parasitol 104: 387-395.

Reece SE, Drew DR, Gardner A 2008. Sex ratio adjustment and kin discrimination in malaria parasites. Nature 453: 609-614.

Reece SE, Duncan AB, West SA, Read AF 2005. Host cell preference and variable transmission strategies in malaria parasites. Proc $R$ Soc B 272: 511-517.

Robert V, Read AF, Essong J, Tchuinkam T, Mulder B, Verhave JP, Carnevale P 1996. Effects of gametocyte sex ratio on infectivity of Plasmodium falciparum to Anopheles gambiae. Trans $R$ Soc Trop Med Hyg 90: 621-624.

Robert V, Sokhna CS, Rogier C, Ariey F, Trape JF 2003. Sex ratio of Plasmodium falciparum gametocytes in inhabitants of Dielmo, Senegal. Parasitol 127: 1-8.

Sinden RE 1983. Sexual development of malaria parasites. Adv Parasitol 22: 153-216.
Sinden RE, Canning EU, Bray RS, Smalley ME 1978. Gametocytes and gamete development in Plasmodium falciparum. Proc $R$ Soc B 201: 375-399.

Salako LA, Ajayi FO, Sowunmi A, Walker O 1990. Malaria in Nigeria: a revisit. Ann Trop Med Parasitol 84: 435-445.

Sowunmi A, Balogun ST, Gbotosho GO, Happi CT 2009a. Plasmodium falciparum sex ratios in acutely symptomatic children treated with antimalarial drugs. Acta Tropica 109: 108-117.

Sowunmi A, Balogun ST, Gbotosho GO, Happi CT, Adedeji AA, Fehintola FA 2007. Activities of amodiaquine, artesunate, and artesunate-amodiaquine against asexual- and sexual-stage parasites in falciparum malaria in children. Antimicrob Agents Chemother 51: 1694-1699.

Sowunmi A, Fateye BA, Adedeji AA, Fehintola FA, Happi TC 2004. Risk factors for gametocyte carriage in uncomplicated falciparum malaria in children. Parasitol 129: 255-262.

Sowunmi A, Gbotosho GO, Happi CT, Fateye B 2010. Factors contributing to anaemia after uncomplicated Plasmodium falciparum malaria in children. Acta Tropica 113: 155-161.

Sowunmi A, Gbotosho G, Happi C, Folarin O, Balogun T 2009b. Population structure of Plasmodium falciparum gametocyte sex ratios in malarious children in an endemic area. Parasitol Int 58: 438-443.

Sowunmi A, Nkogho OO, Okuboyejo TM, Gbotosho GO, Happi CT, Adewoye EO 2009c. Effects of mefloquine and artesunate-mefloquine on the emergence, clearance and sex ratio of Plasmodium falciparum gametocytes in malarious children. Malaria J 8: 297.

Sutherland CJ, Ord R, Dunyo S, Jawara M, Drakeley CJ, Alexander N, Coleman R, Pinder M, Walraven G, Targett GA 2005. Reduction of malaria transmission to anopheles mosquitoes with a sixdose regimen of co-artemether. PLoS Med 2: e92.

Tchuinkam T, Mulder B, Dechering K, Stoffels H, Verhave JP, Cot M, Carnevale P, Meuwissen JEHT, Robert V 1993. Experimental infections of Anopheles gambiae with Plasmodium falciparum of naturally infected gametocyte carriers in Cameroon: factors influencing the infectivity to mosquitoes. Trop Med Parasitol 44: 271-276.

von Seidlein L, Drakeley C, Greenwood B, Walraven G, Targett G 2001. Risk factors for gametocyte carriage in Gambian children. Am J Trop Med Hyg 65: 523-527.

West SA, Reece SE, Read AF 2001. Evolution of gametocyte sex ratios in malaria and related apicomplexan (protozoan) parasites. Trends Parasitol 17: 525-531.

West SA, Smith TG, Nee S, Read AF 2002. Fertility insurance and the sex ratios of malaria and related hemosporin blood parasites. J Parasitol 88: 258-263.

White NJ, Ho M 1992. The pathophysiology of malaria. In JR Baker, $\mathrm{R}$ Muller (eds.), Advances in parasitology, Academic Press, New York, p. 84-175.

WHO - World Health Organization 2001. Antimalarial drug combination therapy. Report of a WHO technical consultation. Document WHO/CDS/RBM/2001.35, Geneva, 36 pp. 